К.А. Таболина*

\title{
О НЕДОСТАТОЧНОСТИ ПОЛНОМОЧИЙ ПРОКУРОРА ДЛЯ ОБЕСПЕЧЕНИЯ ЭФФЕКТИВНОГО НАДЗОРА В СТАДИИ ВОЗБУЖДЕНИЯ УГОЛОВНОГО ДЕЛА
}

Аннотация: В статье исследуются полномочия прокурора в стадии возбуждения уголовного дела и проблема их недостаточности для осуществления эфрективного надзора за прочессуальной деятельностью органов предварительного расследования. Автором критически оценены внесённые в 2007 году изменения досудебного производства, поскольку они противоречат как международно-правовым стандартам, так и российскому законодательству. Рассмотрены наиболее значимые последующие реформе досудебного производства изменения, которые вернули прокуратуре часть надзорных полномочий, в том числе и в стадии возбуждения уголовного дела. Указанные изменения в целом можно оченить позитивно с точки зрения упрочения роли прокурора, однако прослеживается явная непродуманность принятых норм, заключающаяся в их неоднозначном понимании, а также в наличии необъяснимых законодательных ошибок. Кроме того, приведены и проанализированы актуальные статистические данные Генеральной прокуратуры Российской Федерации, Прокуратуры города Москвы, Прокуратуры Московской области. Автором внесены предложения по совершенствованию полномочий прокурора в стадии возбуждения уголовного дела. Сделан вывод о необходимости расширения объёма надзорных полномочий прокурора на основе серьёзного концептуального подхода при ресормировании прокурорского надзора и всего досудебного производства уголовного процесса России. Статья рассчитана на практикующих юристов, преподавателей, аспирантов, студентов юридических вузов, а также всех интересующихся уголовно-прочессуальным правом.

Ключевые слова: юриспруденция, прокурор, прокурорский надзор, полномочия прокурора, недостаточность полномочий прокурора, досудебное производство, возбуждение уголовного дела, реформа досудебного производства, органы предварительного следствия, органы дознания.

DOI: 10.7256/1994-1471.2014.6.10358

$B$ настоящее время продолжается реформирование досудебного производства уголовного процесса России. В особенности преобразования касаются контроля и надзора за предварительным расследованием. Актуальность данному вопросу существенно придаёт принятие Федерального закона от

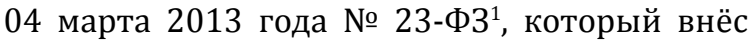
революционные изменения и в стадию возбуждения уголовного дела, и в стадию предварительного расследования.

Вышеуказанный Федеральный закон значительно изменил порядок рассмотрения сообщения о преступлении: теперь стало возможно

Федеральный закон от 04 марта 2013 г. № 23-Ф3 «О внесении изменений в статьи 62 и 303 Уголовного кодекса Российской Федерации и Уголовно-процессуальный кодекс Российской Федерации» // СЗ РФ. 2013. № 9. Ст. 875 . производство большого числа следственных и иных процессуальных действий до возбуждения уголовного дела, более того, полученные в ходе доследственной проверки сведения могут быть использованы в качестве доказательств. Такие нововведения затрагивают интересы лиц, участвующих в производстве процессуальных действий, порождают возможность существенного ограничения конституционных прав и свобод личности и определяют необходимость установления дополнительных уголовно-процессуальных гарантий на стадии возбуждения уголовного дела. В этой связи огромное значение имеет своевременный и эффективный надзор прокурора как гаранта обеспечения законности в государстве. Однако в 2007 году традиционные формы и методы прокурорского надзора за досудебным производством были кардинально реформированы, а полномочия прокурора с тех пор не отличаются постоянством.

(C) Таболина Ксения Андреевна

* Аспирантка кафедры уголовно-процессуального права, Московский государственный юридический университет имени О.Е. Кутафина (МГЮА) [kysi-kyss@yandex.ru] 123995, Россия, г. Москва, ул. Садовая-Кудринская, д. 9. 
Так, в 2007 году Федеральным законом от 05 июня 2007 года № 87-Ф3² были внесены коренные изменения в нормы Уголовно-процессуального кодекса Российской Федерации, регулирующие стадии досудебного производства. Тем самым была предпринята попытка разделения функций предварительного расследования и прокурорского надзора в уголовном судопроизводстве. В результате проведённой реформы досудебного производства к руководителям следственных органов от прокуроров перешла значительная часть полномочий, среди которых - право возбуждать уголовное дело, давать согласие следователю на возбуждение уголовного дела и право отменять незаконные или необоснованные постановления следователя. Это вызывает особый интерес, поскольку проведённые преобразования досудебного производства противоположно коснулись надзора прокурора за другой формой предварительного расследования - дознанием, что является парадоксом: ведь возможность существенного ограничения конституционных прав и свобод личности при производстве предварительного следствия, осуществляемого, как правило, по делам о тяжких и особо тяжких преступлениях, намного выше. Следовательно, объём надзорных полномочий прокурора при производстве предварительного следствия не может быть меньше, чем при производстве дознания. В целом реформа досудебного производства 2007 года подверглась немалой критике и породила дискуссии и в научных кругах ${ }^{3}$, и у практических работников.

Внесённые в 2007 году изменения в УПК РФ вступили в противоречие как с международноправовыми стандартами, так и с российским законодательством. В частности, принятые нормы не согласуются с Рекомендацией № $\mathrm{R}$ (2000) 19 Комитета министров Совета Европы «0 роли прокуратуры в системе уголовного правосудия» ${ }^{4}$ в п. 2 которой указано: «Во всех

\footnotetext{
2 Федеральный закон от 05 июня 2007 года № 87-Ф3 «О внесении изменений в Уголовно-процессуальный кодекс Российской Федерации и Федеральный закон “О прокуратуре Российской Федерации"» // СЗ РФ. 2007. № 24 . Ст. 2830 .

3 См., например: Гаврилов Б. Я. Федеральный закон от 5 июня 2007 года № 87-Ф3: мнение специалиста и учёного // Российская юстиция. 2007. № 7. С. 60-64; Крюков В. Ф. Полномочия прокурора в досудебном производстве по уголовным делам: современность и перспективы // Журнал российского права. 2007. № 10. С. 61-70; Халиулин А. Полномочия прокурора по надзору за процессуальной деятельностью органов предварительного следствия // Законность. 2007. № 9. С. 15-20.
}

Рекомендация № $\mathrm{R}$ (2000) 19 Комитета министров Совета Европы государствам-членам «О роли прокуратуры в системе уголовного правосудия» (приня- системах уголовного правосудия прокуроры: решают вопрос о возбуждении или продолжении уголовного преследования; поддерживают обвинение в суде; могут обжаловать или давать заключения по жалобам на все или некоторые решения суда (курсив мой. - К.T.)». Указанные изменения также не соответствуют Концепции судебной реформы в Российской Федерации ${ }^{5}$, положения которой официально не отменены и предусматривают сохранение за прокурором функции процессуального руководства расследованием, а среди полномочий называют возбуждение уголовного дела и передачу его следователю для производства предварительного следствия. Сейчас, как мы полагаем, очевидные ошибки 2007 года были выявлены и по настоящее время исправляются, а реформа досудебного производства пока не завершена. Наиболее образно это подтверждают изменения, внесённые Федеральным законом от 28 декабря 2010 г. № 404-Ф3', которые вернули прокуратуре часть надзорных полномочий, в том числе и в стадии возбуждения уголовного дела.

В соответствии с вышеуказанным Федеральным законом ч. 2 ст. 37 УПК РФ дополнилась пунктом 5.1, согласно которому прокурор среди прочего вправе истребовать и проверять законность и обоснованность решения следователя или руководителя следственного органа об отказе в возбуждении уголовного дела и принимать по нему решение в соответствии с УПК РФ. Теперь согласно новой редакции УПК РФ прокурор вправе изымать для передачи следователю Следственного комитета РФ и передавать от одного следственного органа другому не только уголовные дела, но и материалы доследственной проверки. В статье 140 УПК РФ появился новый повод для возбуждения уголовного дела - постановление прокурора о направлении соответствующих материалов в орган предварительного расследования для решения вопроса об уголовном преследовании. Однако даже здесь, на наш взгляд, опять прослеживается непродуманность принятых норм.

Так, ч. 2 ст. 37 УПК РФ дополнена п. 5.1, в котором указано, что в ходе досудебного произ-

та Комитетом министров Совета Европы 06 октября 2000 г. на 724-м заседании представителей министров) // Журнал российского права. 2001. № 8. С. 65-70.

Постановление Верховного Совета РСФСР от 24 октября 1991 г. № 1801-1 «О Концепции судебной реформы в РСФСР» // Ведомости СНД и ВС РСФСР. 1991. № 44. Ст. 1435.

6 Федеральный закон от 28 декабря 2010 г. № 404-Ф3 «О внесении изменений в отдельные законодательные акты Российской Федерации в связи с совершенствованием деятельности органов предварительного следствия» // С3 РФ. 2011. № 1. Ст. 16. 
водства прокурор уполномочен «истребовать и проверять законность и обоснованность решений следователя или руководителя следственного органа об отказе в возбуждении, приостановлении или прекращении уголовного дела и принимать по ним решение в соответствии с настоящим Кодексом». Данное нововведение хоть и можно оценить позитивно с точки зрения упрочения роли прокурора в уголовном судопроизводстве России, но всё-таки оно не безупречно и по форме, и по содержанию. В этой связи совершенно справедливо отмечает В.А. Лазарева: «Дополнение, надо сказать, весьма сомнительное как с точки зрения формулировки, т.к. законодатель не потрудился согласовать слова в этом предложении (получилось, что прокурор может «истребовать законность и обоснованность решений»), так и по существу. Право прокурора истребовать названные решения следователя или руководителя следственного органа с неизбежностью вытекает из невыполнения органами расследования обязанности незамедлительно направить прокурору копию постановления...» ${ }^{7}$. Действительно, согласно ч. 4 ст. 148 УПК РФ копия постановления об отказе в возбуждении уголовного дела обязана быть направлена прокурору в течение 24 часов с момента вынесения соответствующего постановления, а необходимость проверки законности и обоснованности указанного решения следует из надзорной функции прокурора, установленной ч. 1 ст. 37 УПК РФ. Такой непродуманностью правовой нормы, на наш взгляд, поставлена под сомнение компетентность органов предварительного следствия. Ясна и невозможность истребования прокурором законности и обоснованности решений следователя или руководителя следственного органа. Возможно, подразумевается истребование материалов уголовного дела и материалов проверки сообщения о преступлении, но по неопределённой причине это не указано в рассматриваемом пункте ч. 2 ст. 37 УПК РФ. В любом случае такая формулировка порождает закономерные вопросы в научных кругах: «Распространяется ли право прокурора истребовать «нечто» для проверки на материалы уголовного дела, без которых проверка не только обоснованности, но часто и законности невозможна, или оно ограничено только постановлением? Нужен ли для получения постановления и материалов дела мотивированный письменный запрос?» ${ }^{8}$. В целях повышения эффективности

Лазарева В. А. Долгожданные изменения в статусе прокурора (Закон от 28 декабря 2010 г. № 404-Ф3) // Уголовное судопроизводство. 2011. № 3. С. 2.

8 Там же. С. 3. прокурорского надзора за процессуальной деятельностью органов предварительного следствия, а также корректного и единообразного понимания правовой нормы предлагаем изложить п. 5.1 ч. 2 ст. 37 УПК РФ в следующем виде: «истребовать материалы проверки сообщения о преступлении или материалы уголовного дела и проверять законность и обоснованность решений следователя или руководителя следственного органа об отказе в возбуждении, приостановлении или прекращении уголовного дела и принимать по ним решение в соответствии с настоящим Кодексом».

Согласно новой редакции ч. 6 ст. 148 УПК РФ прокурор в срок не позднее 5 суток с момента получения материалов проверки сообщения о преступлении наделяется правом признания постановления руководителя следственного органа, следователя об отказе в возбуждении уголовного дела незаконным или необоснованным и отмены его. Данное решение оформляется мотивированным постановлением прокурора с изложением конкретных обстоятельств, подлежащих дополнительной проверке, которое вместе с материалами незамедлительно направляется руководителю следственного органа. Указанную норму можно соотнести с ч. 4 ст. 146 УПК РФ, устанавливающей, что в случае если прокурор признает возбуждение уголовного дела незаконным или необоснованным, он вправе в срок не позднее 24 часов с момента получения материалов отменить постановление о возбуждении уголовного дела, о чём выносит мотивированное постановление. Но если прокурор отменит постановление о возбуждении уголовного дела, то производство по делу продолжено не будет, а если прокурор вынесет решение об отмене постановления об отказе в возбуждении уголовного дела, то, логически, производство по делу продолжится, должны будут быть произведены следственные действия и приняты соответствующие процессуальные решения. Однако принятие таких решений, как и производство большинства следственных действий, возможно только в рамках возбуждённого уголовного дела, но прокурор не правомочен одним решением с отменой постановления об отказе в возбуждении уголовного дела одновременно возбудить его, он может лишь изложить обстоятельства, которые подлежат дополнительной проверке. Даже в данном случае возбудить уголовное дело вправе только следователь или руководитель следственного органа по своему усмотрению. Кроме того, прокурор не вправе самостоятельно возбудить уголовное дело и в случае отмены в порядке ч. 6 ст. 148 УПК РФ постановления органа дознания, дознавателя об отказе в возбуждении уголовного дела. На 
наш взгляд, это затрудняет возможность расследования уголовного дела по горячим следам, блокирует потерпевшему доступ к правосудию, а также вызывает лишнюю бумажную волокиту. Более того, нами выявлена явная тенденция к ежегодному увеличению количества отменённых прокурором и по его инициативе постановлений об отказе в возбуждении уголовного дела. Так, согласно статистическим данным Генеральной прокуратуры Российской Федерации, прокурором и по его инициативе отменено постановлений органов предварительного расследования об отказе в возбуждении уголовного дела (в Российской Федерации): в 1-м полугодии 2011 года - 1114662, в 1-м полугодии 2012 года - 1257559 (+ 12,8 \%), а в 1-м полугодии 2013 года - уже 1273472 (+ $1,3 \%)^{9}$. Выявленная тенденция свидетельствует о постоянном количественном приросте незаконных или необоснованных постановлений органов предварительного расследования об отказе в возбуждении уголовного дела, отменённых средствами прокурорского надзора. При этом сохраняется возможность повторного вынесения органами предварительного расследования постановлений об отказе в возбуждении уголовного дела, что позволяет утверждать о недостаточности полномочия прокурора только отменяющего решение об отказе в возбуждении уголовного дела. Представляется, что прокурор должен обладать правом вынесения единого постановления об отмене постановления об отказе в возбуждении уголовного дела и о возбуждении уголовного дела ${ }^{10}$.

Неоднозначное отношение у нас вызывает действующая редакция ч. 6 ст. 148 УПК РФ и в части дифференциации порядка осуществления прокурором своего надзорного полномочия в зависимости от формы предварительного расследования. Так, признав постановление

\footnotetext{
9 Основные результаты работы по надзору за исполнением законов, соблюдением прав и свобод человека и гражданина за январь-июнь 2011-2012 гг. [Электронный ресурс] : основные статистические данные о деятельности органов прокуратуры // Генеральная прокуратура Российской Федерации : официальный сайт URL: http:/genproc.gov.ru/stat/data/ (дата обращения: 17.11.2013); Основные результаты прокурорской деятельности за январь-июнь 2013 года [Электронный ресурс] : основные статистические данные о деятельности органов прокуратуры // Генеральная прокуратура Российской Федерации : официальный сайт. URL: http:// genproc.gov.ru/stat/data/ (дата обращения: 17.11.2013).

10 См. об этом также: Таболина К. А. К вопросу о проблемах реализации надзорных полномочий прокурора в досудебном производстве // Перспективы развития уголовно-процессуального права и криминалистики. Материалы 2-й международной научно-практической конференции. Часть 2. 2012. С. 203-204.
}

органа дознания, дознавателя об отказе в возбуждении уголовного дела незаконным или необоснованным, прокурор отменяет его и направляет соответствующее постановление начальнику органа дознания со своими указаниями, устанавливая срок их исполнения. А в случае признания отказа руководителя следственного органа, следователя в возбуждении уголовного дела незаконным или необоснованным, прокурор в срок не позднее 5 суток с момента получения материалов проверки сообщения о преступлении отменяет постановление об отказе в возбуждении уголовного дела, о чём выносит мотивированное постановление с изложением конкретных обстоятельств, подлежащих дополнительной проверке, которое вместе с указанными материалами незамедлительно направляет руководителю следственного органа. Такое различие правового регулирования одинаковых, по сути, общественных отношений вызвало множество дискуссионных вопросов среди специалистов в области уголовного процесса: отличается ли чем-то изложение прокурором конкретных обстоятельств, подлежащих дополнительной проверке, от указаний, которые он даёт дознавателю? Следует ли считать, что дознавателю прокурор не возвращает изученные им материалы проверки сообщения о преступлении? Вправе ли прокурор устанавливать следователю срок исполнения своих указаний? Руководителю следственного органа прокурор обязан направить своё мотивированное постановление незамедлительно, а дознавателю - когда хочет или как придётся ${ }^{11}$ Кроме массы возникших вопросов, рассматриваемое законодательное нововведение подверглось и неоспоримой критике. Так, И.В. Овсянников подчёркивает, что обсуждаемое предписание закона в части, обязывающей прокурора изложить в постановлении руководителю следственного органа, следователю конкретные обстоятельства, подлежащие дополнительной проверке, прямо противоречит ч. 1 ст. 144 УПК РФ, которая предписывает проверять не обстоятельства, а сообщение о любом совершённом или готовящемся преступлении. Более того, данная норма в указанной части противоречит и другим положениям уголовно-процессуального закона: в соответствии со ст. 73 УПК РФ обстоятельства не проверяются, а подлежат доказыванию; согласно ст. 87 УПК РФ прове-

\footnotetext{
11 Лазарева В. А. Долгожданные изменения в статусе прокурора (Закон от 28 декабря 2010 г. № 404-ФЗ). С. 3-4; Ряполова Я. П. Процессуальные действия про-
} курора по надзору за законностью и обоснованностью действий и решений на стадии возбуждения уголовного дела // Российский следователь. 2012. № 14. С. 10-11. 
ряются не обстоятельства, а доказательства ${ }^{12}$. Также мы полагаем неудачной формулировку «мотивированное постановление» прокурора, поскольку в силу действующего принципа законности при производстве по уголовному делу все постановления прокурора должны быть законными, обоснованными и мотивированными (ч. 4 ст. 7 УПК РФ). На наш взгляд, нет никакой надобности в указании в законе на необходимость вынесения прокурором мотивированного постановления в каждом конкретном случае.

Достаточно остро обозначается проблема отмены прокурором незаконного или необоснованного постановления руководителя следственного органа, следователя об отказе в возбуждении уголовного дела в случае пропуска установленного для этого 5-дневного срока. Такое ограничение возможности отмены прокурором незаконного или необоснованного постановления следователя об отказе в возбуждении уголовного дела при наличии, например, данных, указывающих на признаки тяжкого или особо тяжкого преступления, кажется нелогичным, ведь право прокурора отменить такое же постановление дознавателя ограничено только давностью уголовного преследования. Среди специалистов в области уголовно-процессуального права предложено нормативно закрепить положение, согласно которому прокурор по истечении 5-дневного срока, признав постановление руководителя следственного органа, следователя незаконным или необоснованным, выносит мотивированное постановление о направлении материалов руководителю следственного органа для решения вопроса об отмене соответствующего постановления ${ }^{13}$. Такой подход соответствует духу п. 2 ч. 1 ст. 39 и ч. 6 ст. 148 УПК РФ. Однако, по нашему мнению, в данной ситуации более уместно было бы вообще исключить указание на какой-либо срок, и это послужило бы дополнительной гарантией соблюдения законности при вынесении руководителем следственного органа, следователем решения об отказе в возбуждении уголовного дела.

Как отмечалось выше, ст. 140 УПК РФ дополнилась новым поводом для возбуждения уголовного дела - постановлением прокурора о направлении соответствующих материалов в орган предварительного расследования для

12 Овсянников И. В. Прокурорский надзор в стадии возбуждения уголовного дела // Вестник Академии Генеральной прокуратуры Российской Федерации. 2012. № 4 (30). C. $12-13$.

13 Ряполова Я. П. Процессуальные действия прокурора по надзору за законностью и обоснованностью действий и решений на стадии возбуждения уголовного дела. С. 11 . решения вопроса об уголовном преследовании, на вынесение которого прокурор уполномочен п. 2 ч. 2 ст. 37 УПК РФ. На наш взгляд, это является своеобразным восполнением отсутствия у прокурора права на возбуждение уголовного дела, законодательным компромиссом. И данный компромисс уже применяется в прокурорской практике. Так, согласно сведениям о работе прокуроров города Москвы в порядке п. 2 ч. 2 ст. 37 УПК РФ направлено материалов для решения вопроса об уголовном преследовании: в 2011 году - 2101, в 2012 году - 1424, - из них возбуждено уголовных дел: в 2011 году - 1716 (81,7 \% от числа направленных постановлений с материалами), в 2012 году - $1169(82,1 \%)^{14}$. По общим данным Прокуратуры Московской области о надзоре за исполнением законов на досудебной стадии уголовного судопроизводства, прокурорами в порядке п. 2 ч. 2 ст. 37 УПК РФ направлено материалов органам предварительного расследования: в 2011 году - 1063, а в 2012 году - 1351, - из них возбуждено уголовных дел: в 2011 году - 802 (75,4 \% от числа направленных постановлений с материалами), в 2012 году $1155(85,5 \%)^{15}$. Приведённые статистические данные в целом выявляют положительную тенденцию к увеличению количества возбуждённых уголовных дел по постановлению прокурора о направлении соответствующих материалов в орган предварительного расследования для решения вопроса об уголовном преследовании. Однако, на наш взгляд, в указанной статистике прослеживается слишком большой процент отказов органов предварительного расследования в возбуждении уголовных дел. В Москве было отказано в возбуждении уголовных дел по материалам, направленным прокурором в порядке п. 2 ч. 2 ст. 37 УПК РФ, в 2011 году - в 18,3 \% случаев, в 2012 году - в 17,9 \%; в Московской области было отказано в возбуждении уголовных дел в 2011 году - в 24,6 \% случаев, в 2012 году - в 14,5 \%. Таким образом, в среднем за два года в Москве по каждому пятому-шестому постановлению прокурора о направлении соответствующих материалов в орган предварительного расследования для решения вопроса об уголовном преследовании выносилось решение об отказе в возбуждении уголовного дела,

\footnotetext{
14 Сведения о работе прокуроров города Москвы по надзору за исполнением законов на досудебной стадии уголовного судопроизводства за 12 месяцев 2012/2011 гг. [Электронный ресурс] : статистика // Прокуратура города Москвы : официальный сайт. URL: http://www. mosproc.ru/statistics/ (дата обращения: 17.11.2013).

15 Основные статистические данные о деятельности органов прокуратуры области за 2012 год [Электронный ресурс]: статистика // Прокуратура Московской области: официальный сайт. URL: http://mosoblproc.ru/ statistika/ (дата обращения: 17.11.2013).
} 
а в Московской области - по каждому пятому. При этом необходимо учитывать, что в соответствии с ч. 1.1 ст. 148 УПК РФ решение об отказе в возбуждении уголовного дела в связи с мотивированным постановлением прокурора о направлении соответствующих материалов в орган предварительного следствия для решения вопроса об уголовном преследовании по фактам выявленных прокурором нарушений уголовного законодательства, вынесенным на основании п. 2 ч. 2 ст. 37 УПК РФ, может быть принято только с согласия руководителя следственного органа. В этой связи невозможно не согласиться с В.А. Лазаревой, которая полагает, что «массовость такого явления, как необоснованный отказ в возбуждении уголовного дела, требует более эффективного средства прокурорского реагирования, чем бесконечная переписка прокурора с руководителем следственного органа. Поэтому включение постановления прокурора о направлении соответствующих материалов в орган предварительного расследования для решения вопроса об уголовном преследовании в число поводов к возбуждению уголовного дела проблемы никак не решает» ${ }^{16}$.

Кроме того, важнейшее надзорное полномочие прокурора в стадии возбуждения уголовного дела определено в п. 1 ч. 2 ст. 37 УПК РФ, в соответствии с которым прокурор уполномочен проверять исполнение требований федерального закона при приёме, регистрации и разрешении сообщений о преступлениях. Согласно статистическим данным Генеральной прокуратуры Российской Федерации прокуроры используют данное полномочие в полном объёме. Так, в Российской Федерации было выявлено нарушений при приёме, регистрации и рассмотрении сообщений о преступлении: в 1-м полугодии 2011 года - 1386873 (71,1 \% от общего числа выявленных нарушений), в 1-м полугодии 2012 года - 1677659 (68,3 \%), в 1-м полугодии 2013 года - 1734429 (73\%) $)^{17}$. Приведённая статистика наглядно показывает, что большинство нарушений законодательства в

\footnotetext{
16 Лазарева В. А. Долгожданные изменения в статусе прокурора (Закон от 28 декабря 2010 г. № 404-ФЗ). С. 3.

17 Основные результаты работы по надзору за исполнением законов, соблюдением прав и свобод человека и гражданина за январь-июнь 2011-2012 гг. [Электронный ресурс] : основные статистические данные о деятельности органов прокуратуры // Генеральная прокуратура Российской Федерации : официальный сайт URL: http://genproc.gov.ru/stat/data/ (дата обращения: 17.11.2013); Основные результаты прокурорской деятельности за январь-июнь 2013 года [Электронный ресурс] : основные статистические данные о деятельности органов прокуратуры // Генеральная прокуратура Российской Федерации : официальный сайт. URL: http:// genproc.gov.ru/stat/data/ (дата обращения: 17.11.2013).
}

досудебном производстве допускается именно в стадии возбуждения уголовного дела, в этой связи прокурору просто необходимо иметь эффективные надзорные полномочия уже с момента приёма и регистрации сообщения о преступлении. Однако требовать от органов предварительного расследования устранения нарушений, допущенных в стадии возбуждения уголовного дела, в соответствии с п. 3 ч. 2 ст. 37 УПК РФ прокурор не имеет права, поскольку это возможно только в ходе дознания или предварительного следствия, т.е. на стадии предварительного расследования. Является ли это законодательной ошибкой - неясно, но указанная проблема достаточно остро обсуждается в научной литературе ${ }^{18}$. Нам представляется, что для оперативного устранения нарушений законодательства в стадии возбуждения уголовного дела, а также в целях пресечения возможности таких нарушений необходимо наделить прокурора соответствующим полномочием. В этой связи предлагаем изложить п. 3 ч. 2 ст. 37 УПК РФ в следующей редакции: «требовать от органов дознания и следственных органов устранения нарушений федерального законодательства, допущенных при приёме, регистрации и разрешении сообщений о преступлениях, а также в ходе дознания или предварительного следствия».

Итак, реформирование стадии возбуждения уголовного дела, да и всего досудебного производства, не только не завершено, но и требует серьёзного концептуального подхода, позволяющего обеспечить достижение назначения уголовного судопроизводства (ст. 6 УПК РФ). В настоящее время остро стоит проблема недостаточности полномочий прокурора для осуществления эффективного надзора за законностью и обоснованностью решений, принимаемых органами предварительного расследования. В этой связи необходимо расширение объёма надзорных полномочий прокурора на продуманной концептуальной основе, исключающей неоднозначное понимание уголовнопроцессуальных норм и необъяснимые законодательные ошибки. При разработке такого концептуального подхода следует принять за

\footnotetext{
18 См., например: Овсянников И. В. Прокурорский надзор в стадии возбуждения уголовного дела. С. 10; Ряполова Я. П. Процессуальные действия прокурора по надзору за законностью и обоснованностью действий и решений на стадии возбуждения уголовного дела. C. 11; Петров А. Обеспечение прокурором законности в стадии возбуждения уголовного дела // Законность. 2011. № 11. С. 33; Чубыкин А. В. Проблемы обеспечения прокурором законности при приёме, регистрации и рассмотрении заявлений и сообщений о преступлениях (на примере работы Северо-Западной транспортной прокуратуры) // Криминалистъ. 2012. № 1 (10). С. 64.
} 
основу международно-правовые стандарты, учесть накопленный внутригосударственный опыт построения уголовно-процессуального законодательства, а также идею М.С. Строгови- ча: «... прокурор - блюститель закона, на нём лежит обязанность пресекать любое нарушение закона, обеспечивать точное и неуклонное соблюдение и исполнение закона» ${ }^{19}$.

\section{Библиография:}

1. Гаврилов Б. Я. Федеральный закон от 5 июня 2007 года № 87-Ф3: мнение специалиста и учёного // Российская юстиция. 2007. № 7. - С. 60-64.

2. Крюков В. Ф. Полномочия прокурора в досудебном производстве по уголовным делам: современность и перспективы // Журнал российского права. 2007. № 10. - С. 61-70.

3. Лазарева В. А. Долгожданные изменения в статусе прокурора (Закон от 28 декабря 2010 г. № 404-Ф3) // Уголовное судопроизводство. 2011. № 3. - С. 2-5.

4. Овсянников И. В. Прокурорский надзор в стадии возбуждения уголовного дела // Вестник Академии Генеральной прокуратуры Российской Федерации. 2012. № 4 (30). - С. 9-14.

5. Петров А. Обеспечение прокурором законности в стадии возбуждения уголовного дела // Законность. 2011. № 11. - С. 32-37.

6. Ряполова Я. П. Процессуальные действия прокурора по надзору за законностью и обоснованностью действий и решений на стадии возбуждения уголовного дела // Российский следователь. 2012. № 14. - С. 9-11.

7. Строгович М. С. Курс советского уголовного процесса: Основные положения науки советского уголовного процесса. Т. 1. М., 1968. - 470 с.

8. Таболина К. А. К вопросу о проблемах реализации надзорных полномочий прокурора в досудебном производстве // Перспективы развития уголовно-процессуального права и криминалистики. Материалы 2-й международной научно-практической конференции. Часть 2. 2012. - С. 200-206.

9. Халиуллин А. Полномочия прокурора по надзору за процессуальной деятельностью органов предварительного следствия // Законность. 2007. № 9. - С. 15-20.

10. Чубыкин А. В. Проблемы обеспечения прокурором законности при приёме, регистрации и рассмотрении заявлений и сообщений о преступлениях (на примере работы Северо-Западной транспортной прокуратуры) // Криминалистъ. 2012. № 1 (10). - С. 60-64.

\section{References:}

1. Gavrilov B. Ya. Federal'nyi zakon ot 5 iyunya 2007 goda № 87-FZ: mnenie spetsialista i uchenogo // Rossiiskaya yustitsiya. 2007. № 7. - S. 60-64.

2. Kryukov V. F. Polnomochiya prokurora $\mathrm{v}$ dosudebnom proizvodstve po ugolovnym delam: sovremennost' i perspektivy // Zhurnal rossiiskogo prava. 2007. № 10. - S. 61-70.

3. Lazareva V. A. Dolgozhdannye izmeneniya v statuse prokurora (Zakon ot 28 dekabrya $2010 \mathrm{~g}$. № 404-FZ) // Ugolovnoe sudoproizvodstvo. 2011. № 3. - S. 2-5.

4. Ovsyannikov I. V. Prokurorskii nadzor v stadii vozbuzhdeniya ugolovnogo dela // Vestnik Akademii General'noi prokuratury Rossiiskoi Federatsii. 2012. № 4 (30). - S. 9-14.

5. Petrov A. Obespechenie prokurorom zakonnosti v stadii vozbuzhdeniya ugolovnogo dela // Zakonnost'. 2011. № 11. - S. 32-37.

6. Ryapolova Ya. P. Protsessual'nye deistviya prokurora po nadzoru za zakonnost'yu i obosnovannost'yu deistvii i reshenii na stadii vozbuzhdeniya ugolovnogo dela // Rossiiskii sledovatel'. 2012. № 14. - S. 9-11.

7. Strogovich M. S. Kurs sovetskogo ugolovnogo protsessa: Osnovnye polozheniya nauki sovetskogo ugolovnogo protsessa. T. 1. M., 1968. - $470 \mathrm{~s}$.

8. Tabolina K. A. K voprosu o problemakh realizatsii nadzornykh polnomochii prokurora v dosudebnom proizvodstve // Perspektivy razvitiya ugolovno-protsessual'nogo prava i kriminalistiki. Materialy 2-i mezhdunarodnoi nauchno-prakticheskoi konferentsii. Chast' 2. 2012. - S. 200-206.

9. Khaliullin A. Polnomochiya prokurora po nadzoru za protsessual'noi deyatel'nost'yu organov predvaritel'nogo sledstviya // Zakonnost'. 2007. № 9. - S. 15-20.

10. Chubykin A. V. Problemy obespecheniya prokurorom zakonnosti pri prieme, registratsii i rassmotrenii zayavlenii i soobshchenii o prestupleniyakh (na primere raboty Severo-Zapadnoi transportnoi prokuratury) // Kriminalist". 2012. № 1 (10). - S. 60-64.

Материал поступил в редакцию 1 декабря 20132.

19 Строгович М. С. Курс советского уголовного процесса: Основные положения науки советского уголовного процесса. Т. 1. М., 1968. С. 215. 